\title{
Equity reporting: a framework for putting knowledge mobilization and health equity at the core of population health status reporting
}

\author{
Lesley Ann Dyck, MA (1); Susan Snelling, PhD (2); Val Morrison, MA (3); Margaret Haworth-Brockman, MSc (4); \\ Donna Atkinson, MA (5)
}

This evidence synthesis has been peer reviewed.

Tweet this article

\begin{abstract}
The National Collaborating Centres for Public Health (NCCPH) collaborated on the development of an action framework for integrating equity into population health status reporting. This framework integrates the research literature with on-the-ground experience collected using a unique collaborative learning approach with public health practitioners from across Canada.

This article introduces the Action Framework, describes the learning process, and then situates population health status reporting (PHSR) in the current work of the public health sector. This is followed by a discussion of the nature of evidence related to the social determinants of health as a key aspect of deciding what and how to report. Finally, the connection is made between data and implementation by exploring the concept of actionable information and detailing the Action Framework for equity-integrated population health status reporting. The article concludes with a discussion of the importance of putting knowledge mobilization at the core of the PHSR process and makes suggestions for next steps. The purpose of the article is to encourage practitioners to use, discuss, and ultimately strengthen the framework.
\end{abstract}

Keywords: population health status reporting, health equity, inequity, social determinants of health, knowledge mobilization

\section{Introduction}

Describing differences in health status between and within populations or groups is central to population health status reporting in Canada. ${ }^{1}$ However, we are particularly interested in differences in health status that can be judged as systematic, unfair and avoidable. These differences in health outcomes are often described as social inequalities, or inequities, and are rooted in unequal power relationships and structures across societies. ${ }^{2,3}$ In order to address inequities and improve health equity, we must therefore take collaborative action to improve the social determinants at the root of the health disparity, which include a range of social, political and economic factors. ${ }^{4}$ This is at the heart of an equity-integrated population health status reporting process.

The public health sector has a number of roles in addressing the social determinants of health and improving health equity. ${ }^{5}$ The role we focus on in this article is 'assess and report'. Reporting purposefully on differences in health status between socio-economic groups, rather than adjusting for the effect of this difference on health status, has been identified as a promising practice for improving health equity. ${ }^{6}$ Purposeful reporting of health inequities leverages both the core public
Highlights

- Population health status reporting is a core public health practice, but in Canada it does not tend to explicitly describe health inequities or make recommendations for action to improve health equity.

- This project used a unique collaborative learning circle approach to examine how to better integrate a focus on health equity in population health status reporting processes.

- The result of the project is an action framework that puts knowledge mobilization at the centre to support the implementation of a population health status reporting process that is more likely to result in action to improve health equity.

health function of surveillance and the common practice of population health status reporting (PHSR). By assessing and reporting on health inequities, including effective strategies to reduce these inequities, the argument has been made that public health organizations are more likely to take action and be better able to support others to collaborate to decrease health inequities. ${ }^{7}$

We went looking for population health status reports in Canada that demonstrate the effective integration of health equity issues and the social determinants of

\footnotetext{
Author references:

1. National Collaborating Centre for Determinants of Health, St. Francis Xavier University, Antigonish, Nova Scotia, Canada

2. National Collaborating Centre for Methods and Tools, McMaster University, Hamilton, Ontario, Canada

3. Centre de collaboration nationale sur les politiques publiques et la santé, Institut national de santé publique du Québec, Montréal, Quebec, Canada

4. National Collaborating Centre for Infectious Diseases, University of Manitoba, Winnipeg, Manitoba, Canada

5. National Collaborating Centre for Aboriginal Health, University of Northern British Columbia, Prince George, British Columbia, Canada

Correspondence: National Collaborating Centre for Determinants of Health, St. Francis Xavier University, PO Box 5000, Antigonish, NS B2G 2W5; Tel: 902-867-6133; Email: nccdh@stfx.ca
} 
health and found they were not common. When we did find them, there did not seem to be a consistent or standard approach..$^{8-11}$ This led us to ask: What does the effective integration of health equity look like in a PHSR process? What do we need to pay attention to in order to do it well? How does such a process contribute to action on the social determinants of health to improve health equity? While exploring these questions we developed the Equity-Integrated Population Health Status Reporting: Action Framework, ${ }^{12}$ an action framework for the PHSR process that we thought might help to guide public health organizations in their work of 'assessing and reporting' in a manner that would drive action on the social determinants of health and health inequity.

This article introduces the Action Framework and provides the context for its development. We start by briefly describing our learning process, and then situate PHSR in the work of the public health sector. This is followed by a discussion of the nature of evidence related to the social determinants of health as a key aspect of deciding what and how to report. Finally, we make the connection between data and implementation by exploring the concept of actionable information, and then introduce our Action Framework for equityintegrated PHSR. We conclude with a discussion of the importance of putting knowledge mobilization at the core of the PHSR process and make suggestions for next steps.

\section{Methods: our framework development process}

Our learning process was led by the National Collaborating Centre for the Determinants of Health (NCCDH), one of six national collaborating centres for public health established in 2005 to strengthen knowledge translation and exchange for public health in Canada. ${ }^{13}$ A learning circle of health equity champions from across Canada was established by the $\mathrm{NCCDH}$, representing a diversity of perspectives from ten different public health organizations (such as program managers, medical health officers, policy analysts and epidemiologists from health units/ regional health authorities, and provincial public health departments) and universities (researchers specifically). They were tasked with identifying and exploring the core issues associated with integrating health equity into population health status reporting, and identifying promising practices in the Canadian context. This resulted in the Learning Together Series, ${ }^{14}$ a collection of documents describing the learning circle process and the key questions explored during each meeting of the circle. This became the foundation for a collaboration with the other five NCCPH centres to develop the Equity-Integrated Population Health Status Reporting: Action Framework. ${ }^{12}$ This Action Framework was developed and refined through interviews with ten key stakeholders at local, provincial and national levels in Canada. Iterations of the Action Framework were also presented and discussed during workshops at three Canadian public health conferences* and a webinar. ${ }^{\dagger}$ Feedback from over 100 public health practitioners attending these events was collected via notes of the proceedings and evaluations, and used to inform the final version of the framework.

\section{Results: production of an equity- integration population health status report}

\section{What is a population health status report?}

The six core functions of public health in Canada include: population health assessment, health promotion, disease and injury control and prevention, health protection, surveillance, and emergency preparedness and epidemic response. ${ }^{15,16}$ All levels of government (federal, provincial, territorial and their delegated authorities including regional health authorities) perform some or all of these functions. All governments appoint a chief public or medical health officer to provide leadership to their public health efforts in their respective jurisdictions, ${ }^{15}$ with the legislation and roles varying somewhat across provinces and territories.

Reporting is not a core function but is an essential tool for fulfilling the public health mandate across the six core functions. In a summary of the structural profile of public health in Canada, the National Collaborating Centre for Healthy Public Policy found that the mandate to report on population health assessment and surveillance (as the key functions most relevant to population health status reporting) varied across jurisdictions. At the federal level " $\mathrm{t}$ ] he Chief Public Health Officer shall, within six months after the end of each fiscal year, submit a report to the Minister on the state of public health in Canada." 17 An example from the provincial level comes from British Columbia (BC), where the BC Public Health Act stipulates that population health assessment is mainly the responsibility of the Provincial Health Officer (PHO). At the regional level, an example from Manitoba positions population health assessment as a public health function that is partially assumed on the regional level with some of its components instituted by the Regional Health Authorities Act. ${ }^{17}$

\section{Integrating the concept of equity}

For our project, we used a definition of equity-integrated population health status reports to include "any instrument that uses existing scientific and local knowledge to inform decisions, improve health programs, and reduce health inequities." 1,p.2 Population health status reports generally include surveillance and other data, and tend to be used to highlight specific public health issues or topics. ${ }^{1}$ Having said that, one of the challenges of examining health equity in the context of a population health status report is that there is no standardized format, content or process for this report. If we consider PHSR at the broadest level to be a type of population health assessment, we can frame it within the larger context of health knowledge (Figure 1). ${ }^{18}$ Based on this, a population health status report can be understood as a product (e.g., print document, electronic file, or webpage) that provides an assessment of the health of the population and generates actionable public health knowledge. It is based on the same multiple data sources that inform both public health surveillance and public health research (Figure 1). ${ }^{18}$

\section{Characterizing the assessment process and its objectives}

Information about how to undertake an effective and actionable population health status reporting/assessment process is

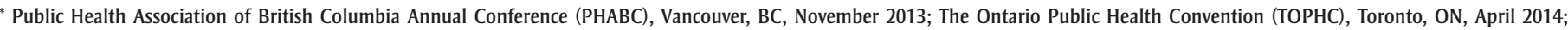
Canadian Public Health Association Annual Conference (CPHA), Toronto, ON, May 2014.

${ }^{+}$Hosted by CHNET-Works!, March 2014. 
FIGURE 1

Public health surveillance in the larger context of health knowledge

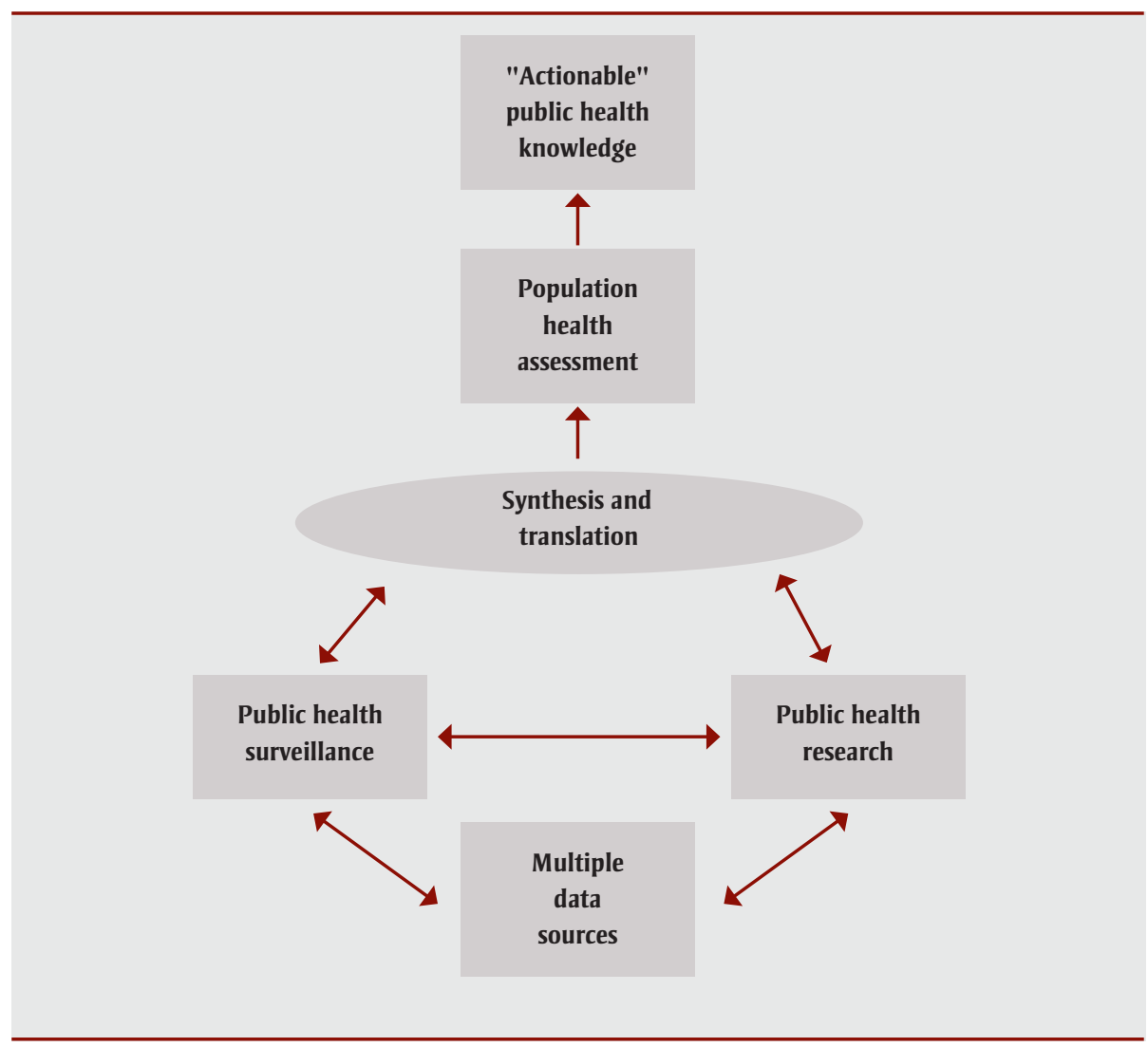

Source: Lexicon, definitions, and conceptual framework for public health surveillance. ${ }^{18, p .13}$

hindered by the lack of established reporting and process guidelines. Community health assessment is a comprehensive community development approach, which is normally part of a larger community health improvement process. ${ }^{19}$ It is often led by community organizations in partnership with the health sector and is most commonly found in the United States. ${ }^{20}$ Like community health assessment, population health status reporting (PHSR) is both the activity and product of identifying and prioritizing population health issues, and it varies according to the size and nature of the community, the lead organization or partners and their goals, the resources available and other local factors. ${ }^{20}$ However, PHSR as a process in Canada is led by the public health sector and is therefore more likely to be undertaken as a method of generating actionable information for the public health sector, not the wider community. As we shall explain, this presents a particular challenge for reporting on health inequities with the objective of generating action to improve the social determinants of health.
In our review of public health reports across Canada, we found that the intended purpose of any particular report was context/topic specific and could include any or all of: a) a program/service focus around improving accountability and assessing quality/effectiveness; b) a population focus to assess changes in health status over time and across geographic regions; and c) a health disparity focus to identify or quantify health differences between groups. ${ }^{21}$ We concluded that the evidence-based and public nature of population health status reports, while not standardized or necessarily inclusive of equity issues, has helped them become a key building block for the construction and realignment of public health policies and programs. ${ }^{1}$

However, there is a second audience of healthy public policy stakeholders outside of the public health sector (including other government departments, municipalities, and community organizations) that is often targeted by these reports, usually through the inclusion of crosssectoral intervention examples and recommendations for action. ${ }^{21}$ With respect to action on the social determinants of health, this second "external" audience is critical. Health equity is determined by social factors related to broad public policy, norms and values-most of which are outside the influence of the health sector. Therefore, if the information is only actionable by the public health sector, it will be insufficient to reduce systemic health inequities.

Our learning circle of public health practitioners and researchers came to the conclusion that a successful report is one that is used. What makes the information in the report actionable is the critical consideration for how to best integrate health equity into a population health status report. What we learned from public health practitioners across Canada is that, in order to ensure a report is used, we need to attend to the format and content of a population health status report, as well as how we engage with stakeholders in the community as part of the data gathering and reporting process.

We will more closely examine engagement as a key principle of PHSR, but first we need to apply an equity lens to what is considered valid evidence for a population health status report.

\section{The evidence base for "health inequity" as a public health issue and area for action}

The evidence base for health inequity as a public health issue and area for action is growing; helped considerably by the establishment of the World Health Organization (WHO) Commission on Social Determinants of Health (CSDH). One of the CSDH knowledge networks created a guide for constructing the evidence base on the social determinants of health, including six conceptual and theoretical problems. ${ }^{22}$ One of the most important points they make for translating knowledge about health inequities into action is that evidence on its own does not ensure success or provide an imperative for action. It needs refinement and engagement of all the players involved in generating evidence, turning it into policy, and turning policy into action and practice. The guide concludes with a recognition that-although we know a lot about the social factors that affect health-what is known is not universal in its applicability. What is known "... must therefore be read through a lens which deals with its 
salience, meaning and relevance in particular local contexts."22,p.218 This underscores the importance of engaging those who understand the local context in the process of gathering, analyzing and reporting data on population heath status in order to effectively integrate health equity considerations.

There are a number of population health status reports in Canada that have tackled the conceptual challenges in different ways in order to effectively integrate a health equity lens..$^{8-11,23-26}$ These reports share the distinction of being explicit about their focus on equity and intention to drive action to improve health equity, and referencing the collaborations and consultations with both organizations and citizens that were necessary to produce the reports. However, these reports do not share a standardized approach, and most are one-time-only reports making it difficult to track change over time and evaluate their collective impact on reducing health inequities. Notable exceptions to the one-time-only reports are the Toronto Unequal City reports from 2010 and 2015, ${ }^{11}$ and the Community Health Assessments from Brandon 2004, 2009, and $2015^{23}$ and Winnipeg 2004, 2009-10 and 2015. ${ }^{26}$

Part of the challenge of tracking change over time has been the diversity of measures and indicators used to assess and monitor health equity. This challenge has been of particular interest over the past decade or so in Canada, resulting in collaborative equity indicator development processes, ${ }^{27,28}$ the development and application of a variety of socio-economic deprivation indices $^{29-31}$ and an equity indicator trend report. ${ }^{32}$ Epidemiologists continue to discuss the best methods to measure and track health equity and inequity, ${ }^{33-36}$ but some argue that it is not the quality of the measures that are the issue, but establishing agreement on which indicators to use and encouraging consistent collection and reporting over time. ${ }^{37,38}$

There continue to be significant conceptual and methodological issues that create barriers to accessing appropriate and highquality data. For example, administrative health data do not normally include income, ethnicity, employment and education data that would allow us to disaggregate population data in a manner that would support a health equity assessment. This makes it very difficult to look at differences in health status between populations; particularly change over time for groups who have been traditionally marginalized and oppressed (e.g. people with disabilities, members of the LGBTQ community). We can also see these challenges in the poor quality and lack of Indigenous health information in Canada, the United States, New Zealand and Australia. Only recently have health surveys in Canada and elsewhere made it possible for people to selfidentify as Indigenous, allowing analysts to better understand health inequities for Indigenous people living off-reserve and in urban settings. Finally, causal pathways between interventions and impacts on health inequities are not clearly understood, ${ }^{22}$ making it difficult to know how and what data to collect as part of standard program evaluations. All of this has impeded " ... the strategic implementation of evidence-based public health interventions aimed at preventing avoidable mortality." 39, p.644

In Canada, data associated with First Nation, Inuit and Métis populations are often not available, incomplete, culturally inappropriate, and impacted by fundamental power and control issues, including jurisdictional arguments among different levels of government. ${ }^{40,41}$ There have been attempts to overcome these challenges, for example through the work of the First Nations Information Governance Centre (FNIGC). The FNIGC has worked to put communities at the heart of the population health status reporting process by developing the First Nations Regional Health Survey (RHS). This has given communities control over the PHSR process, including decisions about participation, choice of indicators, ownership of data and the information reported. ${ }^{42}$ However, this is only a first step as the First Nations RHS does not include the large number of Indigenous people living in urban settings across Canada or other Indigenous groups (e.g. Métis people).

\section{Engagement and actionable health information}

Corburn and Cohen make the case that "drafting, measuring, tracking, and reporting of indicators can be viewed not as a technical process for experts alone, but rather as an opportunity to develop new participatory science policy making, or what we call governance." $38, p .2$ They refer to governance not just of formal institutions, but also "norms, routines and practices" that help shape issues that get onto the health research and policy agenda, the evidence base that is used, and the social actors who are deemed expert enough to participate in these decisions. As a result, it is the process of developing and using indicators of health equity/inequities that create opportunities for new healthy and equitable governance. ${ }^{38}$ This is reinforced in the WHO Europe report on governance for health equity, ${ }^{43}$ where they recommend equity and health equity as essential markers of a fair and sustainable society, requiring evidence and analysis connected to broad sectoral goals and joint assessment methods across sectors and stakeholders.

For public health institutions, using indicators to shape policy and drive action to improve health equity requires capacity to move beyond traditional indicators and engage with a broad range of stakeholders in non-traditional ways. It is important to recognize that

[t]raditional indicators that measure morbidity and mortality tend to either place responsibility for improving health on the medical or public health communities or on vaguely identified institutions such as the economy, education, or built environment. The result is an overemphasis on medical and public health solutions while failing to articulate the specific institutions and policies that might need to change to promote greater health equity. ${ }^{38, p .5}$

A community-engaged approach to PHSR is critical for integrating health equity in a manner that informs the development and delivery of public health programs and services, but also drives intersectoral action on health inequity. This requires that the public health sector move beyond traditional monitoring and surveillance approaches and not be limited to population health status defined by aggregating individual-level health data. Given that evidence is never free of values, if we do not apply an equity lens to collecting, analyzing and synthesizing evidence, we run the risk of ignoring systemic power and oppression issues potentially embedded in population health status measures.

By adopting a community-engaged approach to the 'assess and report' role, the public health sector can benefit from the power of PHSR to blend evidence with values-in this case values of equity and fairness. A community-engaged approach to PHSR 
makes these values explicit in evidence and increases the potential of the evidence to be actionable. The Action Framework identifies three essential components guiding the engagement process for equity-integrated PHSR, including communicate, collaborate, and apply a health-equity values lens ${ }^{12}$ (see the "knowledge mobilization core" in Figure 2).

\section{Discussion: an action framework for PHSR}

In traditional population health status reports, the knowledge to action process emphasizes evidence and concludes with a summary of health status. In reporting processes oriented to action, however, the knowledge mobilization approach combines research knowledge with other types of knowledge and turns them into policy recommendations to drive practice. Although this action-oriented approach to PHSR is less common, there are increasing numbers of examples in Canada. ${ }^{9,11,24}$

\section{Orientation to action}

We are proposing a PHSR framework that is oriented to action, putting equityinformed knowledge mobilization at the core and surrounded by population health status reporting steps, as depicted in Figure 2. Although improved equity in population health status is the intended long-term outcome, the framework is unique in that it includes outcomes to ensure "the community is better equipped to take action to address health equity issues"12,p.9 and therefore puts local intersectoral leadership at the very centre. The framework also identifies roles and specific outcomes for each of the three core stakeholder groups as a result of engaging in this process, including public health, community partners, and researchers.
The Action Framework draws from two similar evidence-driven frameworks: the Evidence informed public health model from the National Collaborating Centre for Methods and Tools (NCCMT) ${ }^{44}$ and the Action Cycle developed by the Robert Wood Johnson Foundation (RWJF). ${ }^{45}$ A brief summary of our framework is provided here, but a complete description-including promising-practice examples-can be found in the document Equity-Integrated Population Health Status Reporting: Action Framework ${ }^{12}$ available from the NCCDH website.

\section{Knowledge mobilization}

The knowledge mobilization core of the framework is the foundation for the essential knowledge synthesis, translation and exchange that happens throughout the PHSR process. It is specific to the intended users of the framework (intersectoral community leadership) and is based on a

FIGURE 2

\section{Equity-Integrated Population Health Status Reporting: Action Framework}

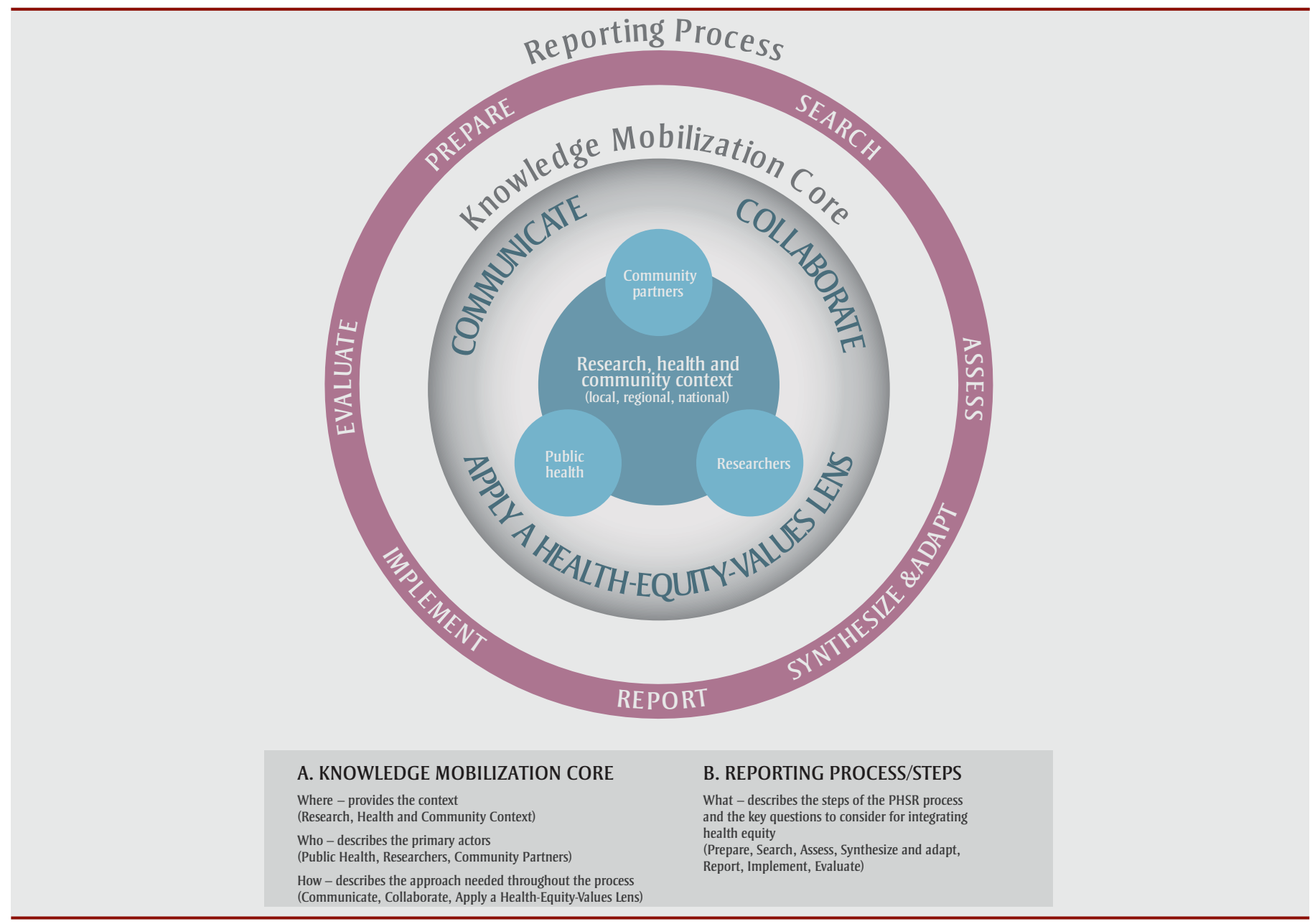

Source: Summary - Equity-Integrated Population Health Status Reporting: Action Framework. ${ }^{49, p .2}$ 
collaborative approach that integrates health equity throughout. It includes three main elements related to where, who, and how (see Box 1). Concrete examples of strong knowledge mobilization for an equity-integrated PHSR approach in Canada and internationally can be found in the Action Framework document. ${ }^{12}$ These include reports that apply an explicit health equity lens, as well as those that provide

\section{BOX 1}

\section{Knowledge mobilization core}

Where - a PHSR process can be done at any level: local, regional, or national. At each level there are different people, organizations, political cultures, and available data. Ultimately, however, the community context and local issues inform the reporting process, and are impacted by it as part of the larger system(s). Over time, the community is better equipped to take action to address health equity issues, and the outcome is improvement in health equity within the local community context.

Who - the primary actors in a strong equity-integrated population health status reporting process are the public health sector, community partners, and researchers; a process led by any actor alone is less likely to result in action. The capacity for leadership and action of each is critical to being able to effectively integrate health equity into a PHSR process. The public health sector is essential in implementing PHSR, and public health actors and advocates are well positioned to provide leadership for an effective PHSR process. Community partners (including government, community organizations and other grassroots leaders) are critical throughout the entire process, and researchers working in a variety of settings and disciplines are important at different points in the process.

How - There is no 'one size fits all' approach to mobilizing knowledge in a PHSR process. However, there are principles that are essential to apply throughout the process, which have been captured in the framework as a series of questions that must be considered. These questions can be clustered into three groups: a) Apply a health-equity-values lens, b) Collaborate, and c) Communicate.

Source: Adapted from Summary - Equity-Integrated Population Health Status Reporting: Action Framework..$^{49, p .3}$ good examples of collaboration and communication practices around health equity and PHSR.

\section{Steps for developing and implementing reports}

The 'reporting process/steps' in our framework include seven steps for developing and implementing PHSR. Each step includes key questions to guide activities to ensure the right structures are implemented to support the work of the equityintegrated PHSR process (see Box 2). Just as we did for the knowledge mobilization core of the framework, we identified a number of promising practices in association with one or more of the seven steps of the reporting process. These can also be found in the Action Framework document. ${ }^{12}$
As a side note, the one step in the process that we were unable to find a promising practice for is the 'evaluate' step. One of the challenges around evaluating outcomes such as the impact of policy changes is the long-term nature of the process. As Hilary Graham has pointed out, this has an impact on political commitment to greater health equity, which “... may quickly wane, particularly if the policy changes ... prove insufficient to secure a narrowing of inequalities ... within the short time periods that governments typically set for their policy goals." "46,p.475 Through our consultation process we learned from some informants that they are either evaluating or planning to evaluate their PHSR activities, but we were not able to document concrete examples. As a next step in developing the

\section{BOX 2}

\section{Key questions for each of the seven steps of the equity-integrated PHSR process}

1. Prepare - Who needs to be part of the process? What are the key questions and issues/problems? In what ways are equity values integrated into our investigation questions?

2. Search - What is the best way to find the relevant research evidence? What indicators will help us answer the research question? What other data are available? Do we need to develop a plan to collect additional data?

3. Assess - What are the data sources and the quality of the data? What limitations are inherent in the sources and data? Is there evidence available from other quantitative, qualitative or participatory research that can be used to complement the data? How do research approaches, data collection and analysis integrate health equity values? Do the various indicators adequately measure both assets and deficits? How well are population demographics disaggregated by geographic, economic and social characteristics?

4. Synthesize and adapt - How can we synthesize, adapt and integrate different types of evidence to paint a more complete picture of inequities? What recommendations can we make for practice based on the available evidence? How are health equity values integrated into our recommendations? How do the recommendations relate to the local context?

5. Report - Who is our audience and what is the best way to communicate what we have learned?

6. Implement - How can we frame the findings so that they engage everyone? What is the best way to explore potential actions, spanning from community mobilization to policy development? How can we collaborate to implement these potential actions?

7. Evaluate - How well did the PHSR process contribute to achieving our organizational goals for the report, where improved equity is included and integrated among those goals? In what ways did increased community capacity to take action on the social determinants of health and health equity result from the process?

Source: Adapted from: Equity-Integrated Population Health Status Reporting: Action Framework. ${ }^{12, \mathrm{p} 35}$ 
equity-integrated PHSR framework, it will be important to seek out and learn from any evaluations that have been undertaken.

\section{Conclusion: contribution and further development of the action framework}

As our learning circle and other public health informants told us, a report that doesn't get used won't help us to improve health equity. ${ }^{21}$ As a result, knowledge mobilization is a central feature of an equity-integrated PHSR framework. We learned that an equity-integrated PHSR process needs to be built around an iterative process that can be applied to fit the context and capacity of stakeholders, and that can draw on promising practices from other disciplines and jurisdictions. In our conversations with a range of public health practitioners, we also learned that to do it well, equity-integrated PHSR must be transparent in how it brings together evidence and social justice values. This makes it more likely that the data will be used to inform other larger processes, including community health assessment and improvement, antipoverty initiatives and sustainable development work, all of which will contribute to improved health equity.

Although 'evaluate' is an important step in the framework, we were not able to find evaluations describing how PHSR contributes to action on the social determinants of health specifically. Collectively, we need to strengthen the evidence base for 'assess and report' as a promising public health practice to address health inequities. ${ }^{14}$ We propose two main areas of inquiry and look forward to supporting research-to-practice collaborations in these areas:

(1) an assessment of current PHSR processes being implemented by public health in Canada, with the objective of evaluating both the processes and outcomes, including policy change ${ }^{47}$

(2) the development of clear performance guidelines for PHSR that effectively integrate health equity, as well as organizational and healthy public policy objectives $^{48}$

Our hope is that this framework will contribute to the improvement and application of population health status reporting to advance health equity in Canada. We look forward to hearing from public health organizations about how they are using their own PHSR processes to improve health equity in their communities.

\section{Acknowledgments}

Funding for this project was provided from the operating budget of the National Collaborating Centre for the Determinants of Health, which is funded by the Public Health Agency of Canada. Special thanks to Tannis Cheadle for her assistance in developing and writing the Action Framework document. And thanks as always to the many public health practitioners who participated in the learning circle meetings, workshops and webinars, and reviewed many drafts along the way.

\section{Conflicts of interest}

The authors declare that they have no competing interests.

\section{Authors' contributions}

LAD provided leadership to project and conceptualized and wrote the initial draft of the paper. SS, VM, MHB and DA contributed relevant literature from each NCC program and provided feedback to drafts of the paper. All authors approved the final manuscript.

The content and views expressed in this article are those of the authors and do not necessarily reflect those of the Government of Canada.

\section{References}

1. National Collaborating Centre for Determinants of Health. Learning together: what is a population health status report and why is it important? [Internet]. Antigonish (NS): NCCDH, St Francis Xavier University; 2012 [cited 2017 Jul 31]. Available from: http://nccdh.ca /images/uploads/Learning_Circle_3.pdf

2. Braveman PA, Kumanyika S, Fielding J, et al. Health, disparities and health equity: the issue is justice. Am J Public Health. 2011;101:S149-S155. doi: 10.2105 /AJPH.2010.300062.

3. Whitehead M, Dahlgren G. Concepts and principles for tackling social inequities in health: levelling up part 1 [Internet]. Copenhagen (Denmark): World Health Organization; 2006 [cited 2017 Jul 31]. Available from: http:// www.euro.who.int/_data/assets/pdf _file/0010/74737/E89383.pdf
4. National Collaborating Centre for Determinants of Health. Glossary of essential health equity terms [Internet]. Antigonish (NS): NCCDH, St. Francis Xavier University; 2014 [cited 2017 Jul 31]. Available from: http://nccdh.ca /images/uploads/comments/Glossary _EN.pdf

5. National Collaborating Centre for Determinants of Health. Let's talk: public health roles for improving health equity [Internet]. Antigonish (NS): NCCDH, St. Francis Xavier University; 2013 [cited 2017 Jul 31]. Available from: http://nccdh.ca/images/uploads /PHR_EN_Final.pdf

6. Sudbury \& District Health Unit. 10 promising practices to guide local public health practice to reduce social inequities in health: technical briefing [Internet]. Sudbury (ON): Sudbury \& District Health Unit; 2016 [cited 27 Jul 2017]. Available from: http://www.nmpha .org/Resources/Documents / 10 PromisingPractices.pdf

7. National Collaborating Centre for Determinants of Health. Let's talk: health equity [Internet]. Antigonish (NS): NCCDH, St. Francis Xavier University; 2013 [cited 2017 Jul 31]. Available from: http://nccdh.ca/images/uploads /Lets_Talk_Health_Equity_English.pdf

8. Public Health Agency of Canada. The Chief Public Health Officer's report on the state of public health in Canada: addressing health inequalities [Internet]. Ottawa (ON): PHAC; 2008 [cited 2017 Jul 31]. Available from: http:// www.phac-aspc.gc.ca/cphorsphc -respcacsp/2008/fr-rc/pdf/CPHO -Report-e.pdf

9. Lemstra M, Neudorf C. Health disparity in Saskatoon: analysis to intervention [Internet]. Saskatoon (SK): Saskatoon Health Region; 2014 [cited 2017 Jul 31]. Available from: http:// www.caledoninst.org/Special \% 20 Projects/CG-COP/Docs/HealthDisparity Rept-complete.pdf

10. Sudbury \& District Health Unit. Opportunity for all: the path to health equity [Internet]. Sudbury (ON): Sudbury \& District Health Unit; 2013 [cited 2017 Jul 31]. Available from: https://www .sdhu.com/wp-content/uploads /2015/10/Opportunity-for-All-Report_ FINAL_for-web_FileInfo.pdf 
11. Toronto Public Health. The unequal city 2015: Income and health inequities in Toronto: technical report [Internet]. Toronto (ON): Toronto Public Health; 2015 [cited 2017 Jul 31]. Available from: http://www1 .toronto.ca/City \% 200f \% 20Toronto / Toronto \% 20 Public\% 20Health /Performance \% 20\&\% 20Standards /Health \% 20Surveillance \% 20and \% 20 Epidemiology/Files/pdf/Technical \% 20Report \% 20FINAL \% 20PRINT_ AODA.pdf

12. National Collaborating Centre for Public Health and National Collaborating Centre for Determinants of Health. Equity-integrated population health status reporting: action framework [Internet]. Antigonish (NS): NCCDH, St. Francis Xavier University; 2016 [cited 2017 Jul 31]. Available from: http://nccph.ca/images/uploads /general/PHSR_Action_Framework_ EN_final.pdf

13. National Collaborating Centres for Public Health. About us [Internet]. NCCPH; [cited 2017 Jul 31]. Available from: http://nccph.ca/about-us

14. National Collaborating Centre for Determinants of Health. Learning together: how and what we learned about equity-integrated population health status reporting [Internet]. Antigonish (NS): NCCDH, St Francis Xavier University; 2013 [cited 2017 Jul 31]. Available from: http://nccdh .ca/images/uploads/Equity_Integration _EN_Final_En.pdf

15. Marchildon GP. Canada: health system review 2013 [Internet]. Copenhagen: European Observatory on Health Systems and Policies; 2013 [cited 2017 Jul 31]. Available from: http://www .euro.who.int/en/about-us/partners /observatory/publications/health-system -reviews-hits/full-list-of-country-hits /canada-hit-2013

16. Pan-Canadian Public Health Network. Blueprint for a federated system for public health surveillance in Canada: vision and action plan [Internet]. Ottawa (ON): Pan-Canadian Public Health Network; 2016 [cited 2017 Jul 31]. Available from: http://www.phn -rsp.ca/pubs/bfsph-psfsp-2016/index -eng.php
17. National Collaborating Centre for Healthy Public Policy. Structural profile of public health in Canada [Internet]. Montréal (QC): NCCHPP; [cited 2017 Jul 27]. Available from: http://www .ncchpp.ca/710/Structural_Profile_of _Public_Health_in_Canada.ccnpps

18. Hall HI, Correa A, Yoon PW, Braden CR. Lexicon, definitions, and conceptual framework for public health surveillance. MMWR Surveill Summ. 2012;61 (Suppl):10-14.

19. Fawcett S, Holt C, Schultz J. Some recommended practice areas for community health improvement (report to the CDC, office of prevention through healthcare) [Internet]. Kansas: Work Group for Community Health and Development, University of Kansas; 2011 [cited 2017 Jul 31]. Available from: http://ctb.ku.edu/sites/default /files/site_files/recommended_practices _for_enhancing_community_health_ improvement.pdf

20. Association for Community Health Improvement. ACHI community health assessment tool kit [Internet]. Health Research and Educational Trust; 2007 [cited 2017 Jul 31]. Available from: http://www.assesstoolkit.org/

21. National Collaborating Centre for Determinants of Health. Learning together: reviewing evidence on the purpose of population health status reporting [Internet]. Antigonish (NS): NCCDH, St Francis Xavier University; 2012 [cited 2017 Jul 31]. Available from: http://nccdh.ca/images/uploads /Learning_Circle_4.pdf

22. Bonnefoy J, Morgan A, Kelly MP, Butt J, Bergman V. Constructing the evidence base on the social determinants of health: a guide [Internet]. Measurement and Evidence Knowledge Network (MEKN) of the WHO Commission on Social Determinants of Health; 2007 [cited 2017 Jul 31]. Available from: www.who.int/social_ determinants/knowledge_networks / add_documents/mekn_final_ guide_112007.pdf

23. Allan J, McPherson N, Williams C, et al. Prairie mountain health community health assessment 2015 [Internet] Souris (MB): Prairie Mountain Health; 2015 [cited 2017 Jul 31]. Available from: http://www.prairiemountainhealth .ca/images/Community_Health_ Assessment.pdf
24. Winnipeg Regional Health Authority. Health for all: building Winnipeg's health equity action plan [Internet]. Winnipeg (MB): Winnipeg Regional Health Authority; 2013 [cited 2017 Jul 31]. Available from: http://www.wrha .mb.ca/about/healthequity/files /HealthForAll_Documentwithlinks.pdf

25. Vancouver Coastal Health. Reducing health disparities in Vancouver Coastal Health communities: population health priorities [Internet]. Vancouver (BC): Vancouver Coastal Health; 2008 [cited 2016 Jan 11].

26. Centre for Healthcare Innovation and Winnipeg Regional Health Authority. 2014 community health assessment [Internet]. Winnipeg, MB: WRHA \& CHI Evaluation Platform; 2015 [cited 2017 Jul 31]. Available from: http:// www.wrha.mb.ca/research/cha2014 /index.php

27. Provincial Health Services Authority. Development of priority health equity indicators for British Columbia: process and outcome report [Internet]. Vancouver (BC): Provincial Health Services Authority, Population and Public Health Program; 2014 [cited 2017 Jul 31]. Available from: http:// www.phsa.ca/Documents/development ofpriorityhealthequityindicatorsreportw .pdf

28. Pan-Canadian Public Health Network. Indicators of health inequalities. A report from the population health promotion expert group and the healthy living issue group for the Pan-Canadian public health network [Internet]. Pan-Canadian Public Health Network; 2010 [cited 2017 Jul 31]. Available from: http://www.phn-rsp .ca/pubs/ihi-idps/pdf/Indicators-of -Health-Inequalities-Report-PHPEG -Feb-2010-EN.pdf

29. Bell N, Hayes MV. The Vancouver area neighbourhood deprivation index (vandix): a census-based tool for assessing small-area variations in health status. Can J Public Health. 2012;103(Suppl 2):S32.

30. Chateau D, Metge C, Prior H, Soodeen R. Learning from the census: the socio-economic factor index (SEFI) and health outcomes in Manitoba. Can J Public Health. 2012;103(Suppl 2):S27. 
31. Pampalon R, Hamel D, Gamache P, Philibert MD, Raymond G, Simpson A. An area-based material and social deprivation index for public health in Québec and Canada. Can J Public Health. 2012;103(Suppl 2):S22.

32. Canadian Institute for Health Information. Trends in income related health inequalities in Canada: technical report [Internet]. Ottawa (ON): CIHI; 2015 [cited 2017 Jul 31]. Available from: https://secure.cihi.ca /free_products/trends_in_income _related_inequalities_in_canada_2015 _en.pdf

33. Norheim OF. Gini impact analysis: measuring pure health inequity before and after interventions. Public Health Ethics. 2010;3 (3):282-292. doi: 10.1093 /phe/phq017.

34. Harper S, King NB, Meersman SC, Reichman ME, Breen N, Lynch J. Implicit value judgments in the measurement of health inequalities. Milbank Q. 2010;88(1):4-29. doi: 10.1111 /j.1468-0009.2010.00587.x.

35. Asada Y, Hurley J, Norheim OF, Johri M. A three-stage approach to measuring health inequalities and inequities. Int J Equity Health. 2014;13:98. doi: 10.1186/s12939-014-0098-y.

36. Moonesinghe R, Bouye K, PenmanAguilar A. Difference in health inequity between two population groups due to a social determinant of health. Int $\mathrm{J}$ Environ Res Public Health. 2014;11(12):13083. doi: 10.3390 /ijerph111213074.

37. Gakidou E, Fullman N. Monitoring health inequalities: measurement considerations and implications [Internet]. Brisbane (AU): Health Information Systems Knowledge Hub, School of Population Health, University of Queensland; 2012 [cited 2017 Jul 31]. Available from: http://www.healthdata .org/research-article/monitoring -health-inequalities-measurement -considerations-and-implications

38. Corburn J, Cohen AK. Why we need urban health equity indicators: integrating science, policy, and community. PLoS Med. 2012;9(8):e1001285. doi: 10.1371/journal.pmed.1001285.
39. Freemantle J, Ring I, Arambula Solomon TG, et al. Indigenous mortality (revealed): the invisible illuminated. Am J Public Health. 2015; 105(4):644-652. doi: 10.2105/AJPH .2014 .301994 .

40. Adelson $\mathrm{N}$. The embodiment of inequity: health disparities in aboriginal Canada. Can J Public Health. 2005; 6(Suppl 2):S61.

41. King $M$, Smith A, Gracey $M$. Indigenous health part 2: the underlying causes of the health gap. Lancet. 2009;374(9683):76-85. doi: 10.1016/ S0140-6736(09)60827-8.

42. First Nations Information Governance Centre. First Nations regional health survey (RHS) 2008/10: national report on adults, youth and children living in First Nations communities [Internet]. Ottawa (ON): FNIGC; 2012 [cited 2017 Jul 31]. Available from: http://fnigc .ca/sites/default/files/First \% 20 Nations \% 20Regional \% 20Health \% 20 Survey \% 20(RHS) \% 202008-10\%20 -\%20National\%20Report.pdf

43. Brown C, Harrison D, Burns H, Ziglio E. Governance for health equity: taking forward the equity values and goals of health 2020 in the WHO European region [Internet]. Copenhagen (Denmark): World Health Organization Regional Office for Europe; 2013 [cited 2017 Jul 31]. Available from: http:// www.euro.who.int/_data/assets/pdf _file/0020/235712/e96954.pdf

44. National Collaborating Centre for Methods and Tools. Evidence-informed public health [Internet]. Hamilton (ON): NCCMT, McMaster University; 2016 [cited 2017 Jul 31]. Available from: http://www.nccmt.ca/professional -development/eiph

45. Robert Wood Johnson Foundation. County health rankings and roadmaps - action center [Internet]. Robert Wood Johnson Foundation; [cited 2017 Jul 31]. Available from: http://www .countyhealthrankings.org/roadmaps /action-center

46. Graham H. Health inequalities, social determinants and public health policy. Policy Polit. 2009;37(4):463-479. doi: 10.1332/030557309X445618.
47. Embrett MG, Randall GE. Social determinants of health and health equity policy research: exploring the use, misuse, and non-use of policy analysis theory. Soc Sci Med. 2014;108:147155. doi: 10.1016/j.socscimed.2014.03 .004 .

48. Nakaima A, Sridharan S, Gardner B. Towards a performance measurement system for health equity in a local health integration network. Eval Program Plann. 2013;36(1):204-212. doi: 10.1016/j.evalprogplan.2012.03.009.

49. National Collaborating Centres for Public Health and National Collaborating Centre for Determinants of Health. Summary - equity-integrated population health status reporting: action framework [Internet]. Antigonish (NS): NCCDH; 2016 [cited 2017 Jul 31]. Available from: http://nccdh.ca /images/uploads/comments/PHSR _Action_Framework_Summary_EN_ v3.pdf 